\title{
A CASE OF CONGENITAL CIRRHOSIS OF THE LIVER WITH RENAL TUBULAR DEFECTS AKIN TO THOSE IN THE FANCONI SYNDROME
}

\author{
BY \\ MARGARET D. BABER \\ From Edguare General Hospital, Middlesex
}

(RECEIVED FOR PUBLICATION APRIL 12, 1956)

The excretion of abnormal quantities of aminoacids in the urine is known to occur in liver disease when the cells of this organ are unable to metabolize normally, and in certain clinical syndromes in which there is a high renal clearance of amino-acids, but it is only recently that definite patterns of aminoacid excretion have become recognized (Dent, 1952-53). Fanconi (1936) first drew attention to the presence of amino-aciduria in a syndrome occurring in children, previously described by several authors including himself, and characterized by dwarfism, vitamin D-resistant rickets, glycosuria of the renal type and excessive excretion of water and phosphate. The amino-acid pattern of the urine in this syndrome has now been shown to be constant and characteristic, but it appears that other closely allied syndromes with their own characteristic amino-acid excretion patterns may also be recognized. For this reason the following case history of a patient with some unusual clinical features and biochemical findings is placed on record.

\section{Case Report}

The patient was 9 months old when admitted to hospital on June 3,1954, complaining of failure to gain weight for three months, abdominal distension, offensive stools and nasal discharge since the age of 3 weeks.

He was the first child of healthy, unrelated parents, a little premature but in a satisfactory condition at birth (weight $5 \mathrm{lb}$.). He was breast fed for two weeks only, then put on National dried milk. He was said at the time of admission to have been quite well until 6 months old but later, when she had another child, his mother said she realized he had never been really normal. At 3 weeks his stools became loose and offensive and his abdomen distended, but he had a good appetite and gained weight steadily till 6 months when he weighed $16 \mathrm{lb} .14 \mathrm{oz}$. His weight fluctuated after this and was $16 \mathrm{lb}$. $11 \frac{1}{2} \mathrm{oz}$. on admission at 9 months. He started mixed feeding at 7 months and took it well, his diet being satisfactory. He had also received adequate supplements of 'adexolin' and orange juice.
Examination showed a small, thin, ill-looking. apyrexial child (Fig. 1) with prominent eyes, a very distended abdomen and copious nasal discharge. Small glands were palpable on both sides of the neck and in the

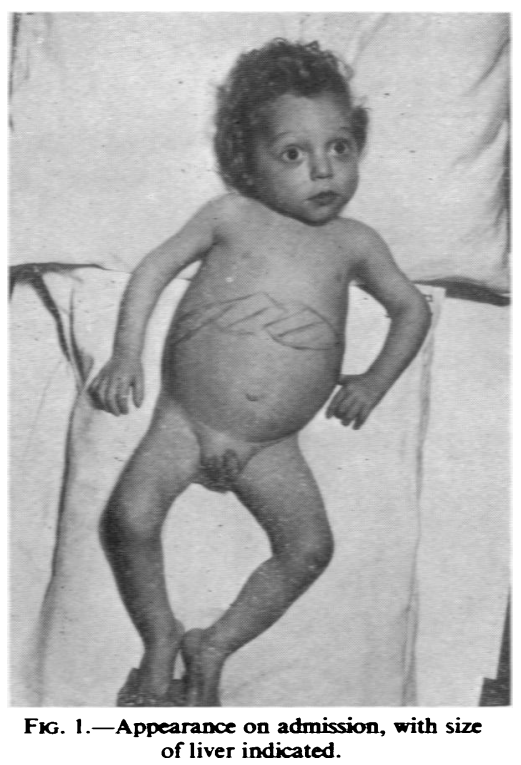

right axilla, but there was no clinical evidence of tonsillar infection. Inspection of the chest revealed splayed-out ribs but no sign of rickets. The heart and lungs were normal. The abdomen was distended and tympanitic and the liver, palpable two fingerbreadths below the costal margin, felt hard and its surface slightly irregular. The spleen was just tipped, and faecal masses were also prominent on deep palpation. A lumbar kyphosis was noted and a lateral radiograph of the spine showed wedging of the body of L.1 (Fig. 2). Radiographs of the long bones (Figs. 3 and 4) showed osteoporosis with expansion of the ends of the shafts and thinning of the cortex. A patch test was negative. His haemoglobin was $70^{\circ}$ o and the differential white cell 


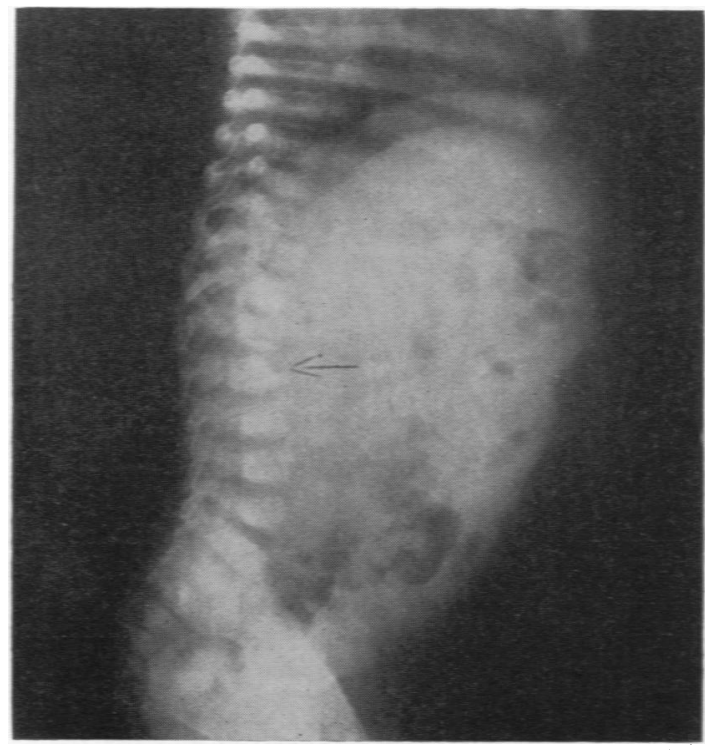

Fig. 2.-Lateral radiograph of the spine indicating wedged vertebra.

count normal. Chest films showed no evidence of lung infection, but fat balance studies, undertaken because the appearance of the stools suggested steatorrhoea, showed that the child was excreting $20 \%$ of the fat ingested, and a provisional diagnosis of fibrocystic disease of the pancreas was made in spite of the negative lung findings. This was abandoned when trypsin was demonstrated to be present in normal amount in the duodenal juice.

On penicillin the

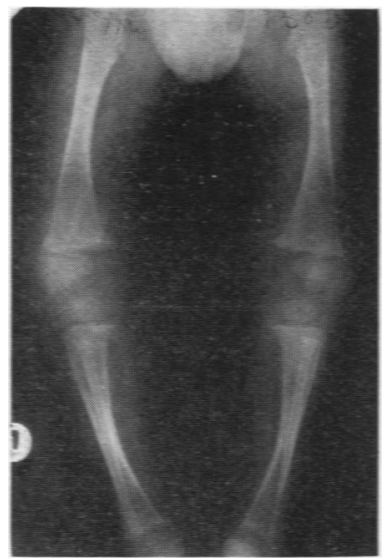

Fig. 4.-Long bones two months after admission, showing osteoporosis but no evidence of rickets.

$$
\text { during the test there }
$$

was marked glycosuria. Liver function tests showed negative thymol turbidity, positive thymol flocculation, normal serum bilirubin and increased prothrombin time, unchanged after vitamin $\mathrm{K}$ had been given. A galactose

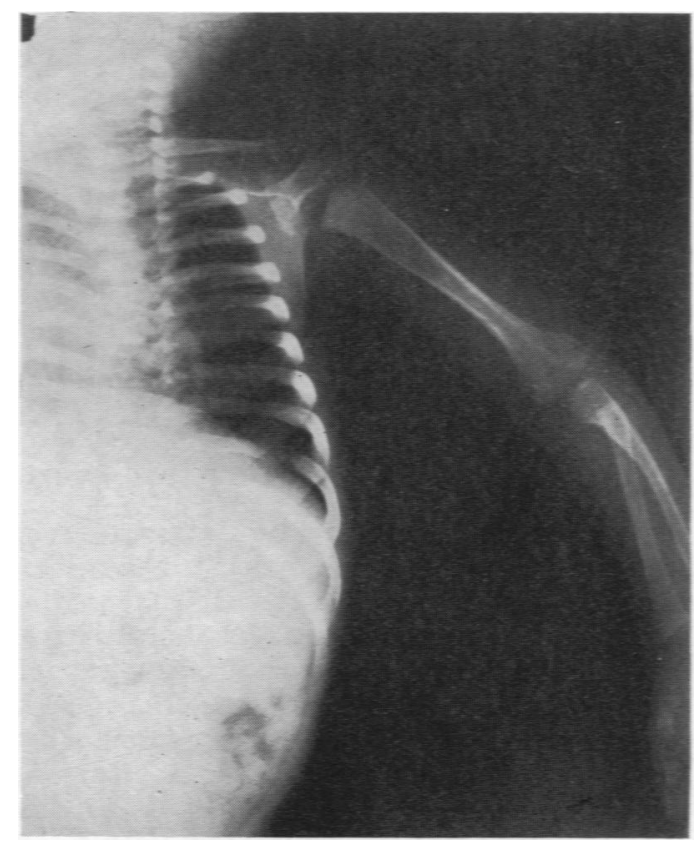

FKG. 3.-Radiograph of long bones (right arm) shortly after admission.

tolerance test gave normal results. The serum alkaline phosphatase was $79 \mathrm{~K}$.-A. units on June 4 .

His urine was now tested for amino-acids by paper chromatography and a gross amino-aciduria of unusual pattern was found. The chromatogram pattern was not that typical of the Fanconi syndrome but was nearer to it than to any other recognized pattern. Of special interest was the relatively high excretion of tyrosine, serine, threonine, tryptophane, histidine, and lysine without increased cystine excretion.

No cystine deposits were seen in the ocular media, including the cornea, on slit-lamp microscopic examination.

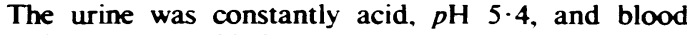
chemistry on June 30 showed:

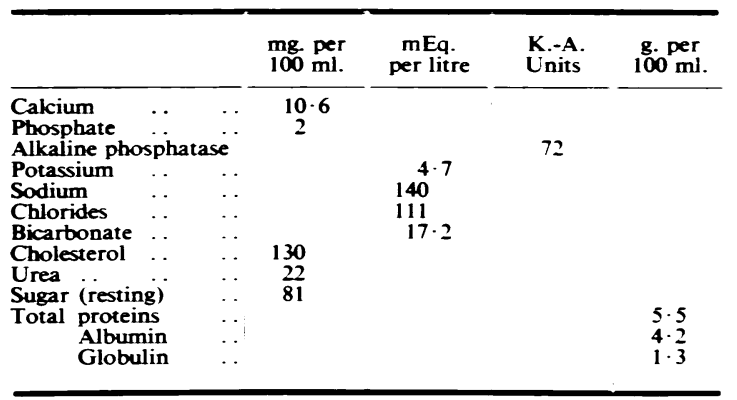

The electrophoretic pattern proved to be normal.

At this point the following diagnoses were considered. Amino-aciduria and mild acidosis with probable cirrhosis 
of the liver suggested a variant of the de Toni-Fanconi syndrome, but the vertebral radiograph was thought to be highly suggestive, if not pathognomonic, of gargoylism or Hurler's syndrome. The enlarged liver and spleen appeared to fit in with this latter diagnosis although the child's facies were not typical. Gaucher's disease was considered, especially in view of the widening of the shafts of the long bones with cortical thinning, but a marrow puncture revealed no Gaucher cells. A diagnosis of primary hepatic disorder was also favoured especially when, as time went on, the liver became harder and somewhat smaller, and 'liver palms' became more striking. However, the amino-aciduria appeared to be mainly renal in origin, the plasma amino-nitrogen being 6.62 and $5.18 \mathrm{mg}$. per $100 \mathrm{ml}$., which is at the high range of normal. Much higher levels are generally found in cases of liver disease associated with amino-aciduria, but it is possible that the plasma level was slightly raised as a result of cirrhosis, and that this contributed to a small extent to the amino-aciduria. Other evidence of renal tubular dysfunction, i.e., glycosuria, polyuria and loss of phosphate and potassium, when taken in conjunction with the amino-aciduria, made a diagnosis of the Fanconi syndrome, or a variant of this syndrome, beyond doubt, with the addition of cirrhosis of the liver a near certainty.

Dr. C. E. Dent, who was consulted about this patient as soon as it became evident that he had a marked amino-aciduria, has very kindly supplied the following report.

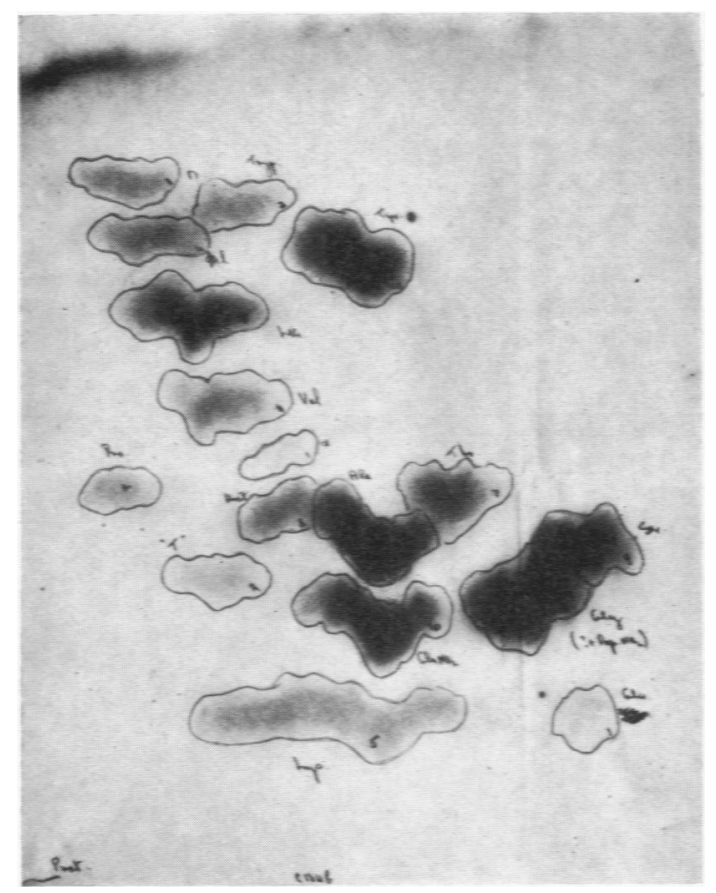

FIG. 5.-Amino-acid chromatogram.
Repeated specimens of urine from the patient were analysed on two-way paper chromatograms using standard procedures and obtained from the patient during the time covering his first admission to hospital until his death. All these specimens showed a gross amino-aciduria in confirmation of the original findings of Miss E. W. M. Johnson. Whereas the spots on the amino-acid chromatogram (Fig. 5) showed a generalized excretion of aminoacids, the pattern was not the same as usually occurs in a case of Lignac-Fanconi disease (cystinosis). The especial characteristics of the pattern were that it contained relatively large quantities of tyrosine, serine, threonine and histidine. There were also excessive quantities of tryptophane and methionine.

Treatment and Progress. An attempt was made to correct the slight acidosis and tendency to low serum potassium (lowest estimation $3.9 \mathrm{mEq}$./litre) by giving sodium and potassium bicarbonate up to a total of 9 g. per day, without any effect, and this therapy was abandoned after one month. 'Calciferol', $1 \mathrm{mg}$. daily $(40,000$ units), was also given for three weeks from the middle of August but serum inorganic phosphate remained low and alkaline phosphatase high, and this treatment also was discontinued. The child gained $1 \frac{1}{2} \mathrm{lb}$. in weight slowly and intermittently during the four months he was in hospital, although his urinary output and degree of glycosuria increased, and he was finally discharged on October 3, to be observed further in the Out-patient Department. His treatment at this time consisted of iron medication, as he had developed a moderate degree of anaemia ( $\mathrm{Hb} \mathrm{64^{ \circ }}{ }_{0}$, colour index 0.86 ), and ordinary vitamin supplements.

In November he was given 'calciferol', $2 \mathrm{mg}$. $(80,000$ units) daily, as the radiographs of the long bones still showed evidence of osteoporosis and suggested early rickets; also he continued to have a high serum alkaline phosphatase ( $80 \mathrm{~K}$.-A. units) and low serum inorganic phosphate $(1.7 \mathrm{mg} .100 \mathrm{ml}$.). The dose was increased to $3 \mathrm{mg}$. daily in January, 1955, and eventually to $4 \mathrm{mg}$. daily in May, without any change in blood chemistry. Radiographs now showed severe osteoporosis and definite evidence of early rickets (Fig. 6). His weight fluctuated and he was more thirsty than before, his fluid intake being so great as to interfere with his eating when he was on this high dose of 'calciferol', but he tolerated $2 \frac{1}{2} \mathrm{mg}$. (100,000 units) daily quite well. In July, saucerization of the radial and ulnar epiphyses was very obvious radiologically and there was delay in formation of ossific centres. Craniotabes became apparent clinically at this time (Fig. 7), and the costochondral junctions were also enlarged. In August he showed numerous greenstick

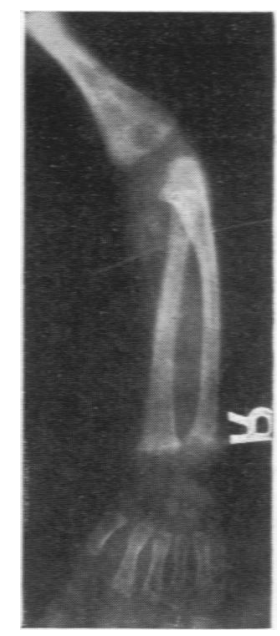

Fig. 6.-Later film of right arm showing evidence of early rickets. 


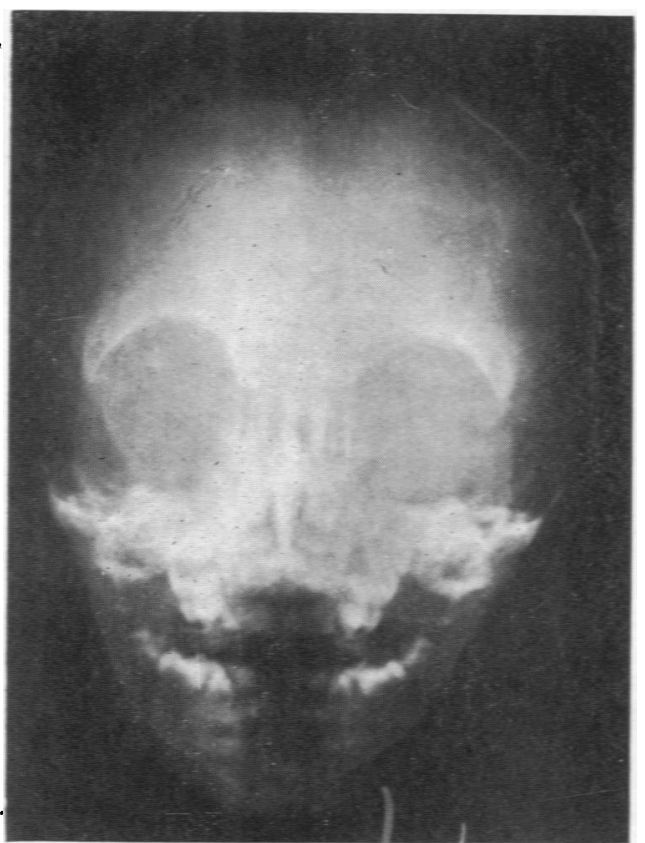

FyG. 7.-Radiograph of the skull showing craniotabes.

fractures of both forearms and now had extensive rachitic changes at the epiphyseal lines (Fig. 8).

In September he appeared to share in an epidemic of diarrhoea affecting several other members of the family and was readmitted with a history of frequent, watery, offensive stools for about one week. He was very dehydrated and his deformed chest, rickety rosary and large, hard, irregular liver were very striking. Serum sodium was $143 \mathrm{mEq}$./1. and cakium was raised to $16: 8$ and serum potassium reduced to $2 \cdot 3 \mathrm{mg}$. per $100 \mathrm{ml}$. The blood urea level was $27 \mathrm{mg}$. per $100 \mathrm{ml}$. In spite of antibiotics, blood transfusion and electrolyte infusions, he failed to rally and died on September 24, 1955.

Necropsy. A necropsy was performed by Dr. J. L. Hamilton-Paterson 14 hours after death. The body was that of a marasmic child, extremely small for 21 years of age, the abdomen was protuberant, and there were multiple bony deformities.

The bones of the skull were extremely thin, especially the parietal bones which were approximately $1 \mathrm{~mm}$. in thickness, and parchment-like in consistency. The pituitary fossa appeared to be greatly reduced in size and distorted, due to a grossly thickened posterior wall of the pituitary fossa, the bone of which was spongy and soft. The cerebral vessels were normal, the brain was macroscopically normal and the pituitary appeared to be intact and possibly smaller than normal.

The pericardial cavity contained a small amount of straw-coloured fluid. The heart was of normal size, and there were no congenital abnormalities; the right ventricle was distended with blood, and the wall of the

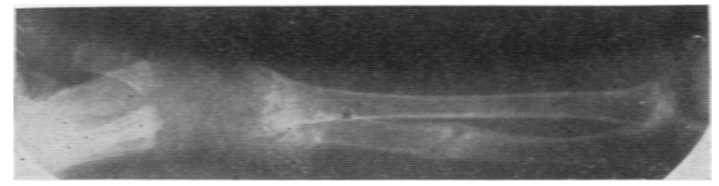

Fig. 8.-Radiograph of the right arm in August, 1955, showing saucerization of radial epiphyses and greenstick fracture of ulna.

left ventricle was perhaps a little thicker than normal. The valves and great vessels were normal in appearance.

The pleural cavities were normal. Both lungs showed congestion and oedema at the bases, but were otherwise normal. The trachea, larynx and bronchi were normal. The mediastinal glands were not enlarged.

The liver was grossly distorted by cirrhotic scarring (Fig. 9). Examination of the external surface suggested that there was little normal liver tissue. The gall bladder, ducts and pancreas appeared normal.

The spleen was moderately enlarged. Its external surface was smooth and normal in appearance, the cut surface firm and congested.

Both kidneys were grossly enlarged, and the foetal lobulation was still evident, but the cut surface showed no obvious disturbance of the normal pattern. There were some pale areas in the cortical tissue in places, and the pelvis of the right kidney was hydronephrotic but the ureter was of normal size. The left pelvis and ureter were normal, and the rest of the urogenital system appeared normal in structure. The bladder was distended with cloudy urine.

The pituitary gland weighed $133 \mathrm{mg}$. The thyroid gland appeared normal. The thymus was present but was not large for the age of the child. Both suprarenals appeared normal, and four parathyroids were found, which together weighed $55 \mathrm{mg}$.

The tongue, pharynx and oesophagus and stomach were normal. The rest of the alimentary canal showed the appearances of paralytic ileus.

The costochondral junctions showed 'rickety-rosary'. Many of the long bones showed deformities in the region of the epiphyses, and this was especially marked at the left wrist. Palpation of the bodies of the vertebrae

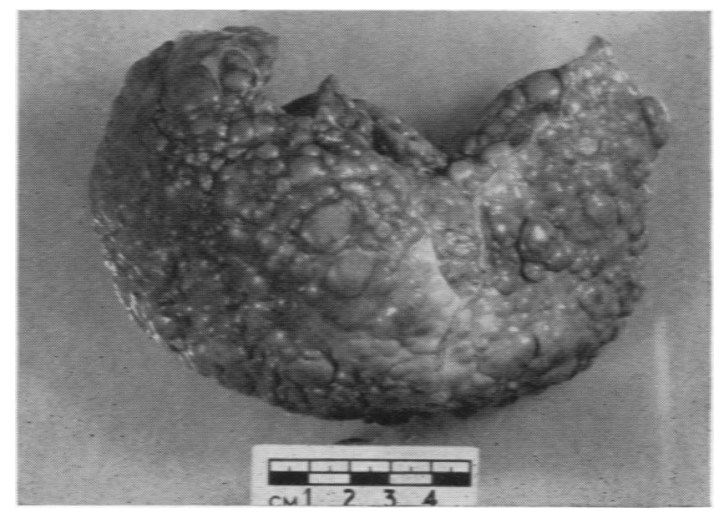

Fig. 9.-Photograph of the liver showing cirrhotic scarring. 
revealed bony abnormalities of several of the lumbar vertebrae.

Histology. The heart was normal and the lungs showed hypostatic congestion only.

The liver showed gross multilobular portal cirrhosis. Mature fibrous tissue was associated with considerable bile duct proliferation and some cellular infiltration suggesting activity. There was evidence of regenerative changes. The most striking abnormality of the hepatic cells was widespread fatty change, in places very well developed; in some areas there were clear signs of adipose transformation and hepatic cell death.

The spleen showed well developed peri-sinusoidal fibrosis and congestion, presumably due to portal hypertension. There was no evidence of cystine deposition.

Pelvic fibrosis of the kidney due to hydronephrosis was seen but remarkably little parenchymal change and only one calcified tubule.

The pancreas, thyroid and three parathyroids were normal, and in the latter no hyperplasia. One piece of thyroid tissue was found. No obvious abnormality was seen in the pituitary.

The aorta was normal.

The tonsil was an active gland with mild acute and chronic inflammatory changes.

A lymph node appeared normal.

In the ribs there was irregularity and thickening of the epiphyseal cartilage. At the epiphyseal line there was irregular calcification and much newly-formed osteoid tissue and 'woven' bone. Some osteo:d tissue was also present along the shaft of the bone. These bony changes were those of rickets. The marrow was cellular and appeared normal.

In the alcohol-fixed lung, spleen, gland and liver, no cystine crystals or deposits were seen.

\section{Discussion}

Cirrhosis of the liver is not an invariable feature of the Fanconi syndrome, although fatty infiltration and focal necrosis are common (Stowers and Dent, 1947). Bickel et al. (1952) attributed the liver changes to cystine storage, but it is noteworthy that there was no evidence of abnormal cystine metabolism in this case. Methionine was lost in excessive amounts in the urine and the liver changes could have been due to this cause, but on the other hand steatorrhoea was apparently present from the age of 3 weeks and was presumably due to hepatic dysfunction, suggesting that cirrhosis of the liver was congenital in origin.

It might be argued that osteoporosis resulted from increased faecal excretion of calcium associated with fat in the stools, but a three-day calcium balance study undertaken in September, 1954, indicated that this was not the case. In the absence of a metabolism bed and other facilities for accurate study, the figures obtained are not worth quoting, but the amount of calcium lost in the urine of this child was far in excess of that lost in the stools, whereas the normal child loses in the urine one-fifth to one-quarter of the amount of calcium excreted in the faeces. This estimation was made before 'calciferol' therapy (which may increase the excretion of calcium by the kidneys) was begun. No attempt was made to carry out a phosphorus balance, the assumption being that hypophosphataemia was similarly due to increased excretion in the urine.

Rickets developed in this patient while he was taking large doses of "calciferol", and he appeared to be wholly resistant to the vitamin. The serum alkaline phosphatase level remained high in spite of the treatment and was obviously uninfluenced by it. The serum phosphate never exceeded $2.3 \mathrm{mg}$. per $100 \mathrm{ml}$, and this fact suggests that vitamin $D$ therapy did not result in increased absorption of phosphorus from the intestine, which is at variance with the experience of Bickel et al. (1952).

No other case of metabolic disturbances has occurred in this family at any time. The patient's younger sister was healthy and well grown at 1 year old, and her urine was normal.

\section{Summary}

An infant suffering from gross amino-aciduria of a distinctive type, with other manifestations similar to those found in the Fanconi syndrome, is described.

Cirrhosis of the liver in an advanced stage was present when the child was first seen at the age of 9 months, and the history suggests that it was congenital in origin.

Rickets developed and progressed in spite of the administration of large doses of "calciferol".

The nature of the metabolic disturbance is discussed very briefly.

I am very much indeb:ed to Dr. C. E. Dent for help and advice in the investigation and treatment of this patient, and for criticism and suggestions. I also wish to thank Miss E. W. M. Johnson for the initial chromatogram and other biochemical investigations, Dr. J. L. Hamilton-Paterson for the necropsy report, Dr. R. A. B. Drury for the histological findings and Mr. H. H. Skeoch for his examination of the ocular media.

\section{REFERENCES}

Bickel. H.. Baar, H. S.. Astley, R.. Douglas, A. A.. Finch. E.. Harris, H.. Harvey. C. C.. Hickmans, E. M., Philpott, M. G.. Smallwood. W. C.. Smellie. J. M. and Teall, C. G. (1952). Acta paediat. (Uppsala), 42. Suppl. 90.

Dent. C. E. (1952-53). In Lectures on the Scientific Basis of Medicine, Vol. 2, p. 213. (British Postgraduate Medical Federation.) London.

Fanconi. G. (1936). Jb. Kinderheilk.. 147. 299.

Stowers. J. M. and Dent, C. E. (1947). Quart. J. Med., 16. 275. 